\title{
Plasma lipid transfer proteins: The role of PLTP and CETP in atherogenesis
}

\author{
Zbyszko Chowaniec ${ }^{A-D}$, Anna Skoczyńska ${ }^{A, C, E, F}$ \\ Department and Clinic of Internal and Occupational Diseases and Hypertension, Wroclaw Medical University, Poland \\ A - research concept and design; $B$ - collection and/or assembly of data; $C$ - data analysis and interpretation; \\ $D$ - writing the article; $E$ - critical revision of the article; $F$ - final approval of the article
}

Address for correspondence

Zbyszko Chowaniec

E-mail:zbyszko3@poczta.onet.pl

Funding sources

None declared

Conflict of interest

None declared

Received on March 6, 2016

Revised on November 13, 2016

Accepted on December 20, 2016

\begin{abstract}
Cardiovascular diseases are still the main cause of death in Poland and throughout the world. Independent risk factors of cardiovascular disease, in addition to elevated LDL cholesterol, are both low HDL levels and high levels of non-HDL cholesterol. Plasma phospholipid-transfer protein (PLTP) and cholesteryl ester transfer protein (CETP) both play a major role in the metabolism of those lipoproteins. A lack of these proteins increases HDL and lowers LDL levels. In the light of current knowledge, it seems reasonable to search for compounds that may decrease the activity of CETP, and thus reduce the incidence of cardiovascular disease. Whereas on the one hand there are reports about the adverse effect of torcetrapib and the lack of therapeutic effects of dalcetrapib, on the other hand the question arises whether the CETP inhibitors that are currently in clinical trials will rise to the challenges before them. Currently, it is known that the activity of PLTP, while affecting the metabolism of lipoproteins, especially HDL, plays a major role in atherogenesis. Still, there are some contradictions and controversies about the effect of PLTP on reverse cholesterol transport (RCT). There are a number of studies about the role that PLTP plays in the pathogenesis of various diseases. Further studies are needed to clearly determine the impact of PLTP activity on the formation and development of pathological processes in the cardiovascular system.
\end{abstract}

Key words: cholesteryl ester transfer protein, atherogensis, plasma phospholipid-transfer protein

DOI

10.17219/acem/67968

\section{Copyright}

Copyright by Author(s)

This is an article distributed under the terms of the

Creative Commons Attribution Non-Commercial License

(http://creativecommons.org/licenses/by-nc-nd/4.0/) 
Plasma phospholipid-transfer protein (PLTP) belongs to the family of lipid-binding and lipid-transfer proteins. ${ }^{1}$ PLTP's main function is its impact on the distribution and metabolism of high-density lipoproteins (HDL) and reverse cholesterol transfer (RCT). In plasma, PLTP catalyzes the transfer of phospholipids, mainly phosphatidylcholine, between lipoprotein classes. ${ }^{2-4}$ It also plays a role in oxidative stress modulation and in the etiology of neurodegenerative diseases, it may have an impact on the coagulation process and immune functions. ${ }^{3,5,6}$

Cholesteryl ester transfer protein (CETP) belongs to a group of proteins which play a major role in lipid metabolism by transporting cholesteryl esters (CE) from HDL to low-density lipoproteins (LDL), intermediate density lipoprotein (IDL), very low-density lipoprotein (VLDL), and chylomicrons in exchange for triglyceride (TG) transport to HDL. It has been reported that CETP is involved in the genesis of cardiovascular disease by its impact on lipid metabolism. ${ }^{5-7}$

PLTP and CETP are in the family of lipid-transfer proteins, which also includes lipoprotein binding protein (LBP). ${ }^{8,9}$ About 25\% of each of these proteins is shared by all of them, while about $21 \%$ of each total protein is specific to it. ${ }^{10}$ The PLTP gene is located on chromosome $20 .{ }^{11}$ PLTP contains 476 sugar moieties, and its molecular weight is about $80 \mathrm{kDa} .{ }^{1}$ Different sugar residues result in differences in the weights of various proteins. A 3D model of PLTP is a boomerang-shaped particle consisting of 2 domains with similar tertiary structures. Each domain has a binding site for a phospholipid molecule's acyl group. ${ }^{12}$ CETP is a hydrophobic glycoprotein consisting of 476 amino acids with a mass of $53 \mathrm{kDa}$. Its 3D structure resembles a banana shape measuring about $3 \times 3 \times 13 \mathrm{~nm}$. The protein consists of the $\mathrm{N}$-terminal and $\mathrm{C}$-terminal domain of the $\beta$-barrel structure and the central part of the $\beta$-sheet structure that contains the active site. ${ }^{13}$

\section{Regulation of activity and concentration of lipid transfer proteins}

PLTP expression is PPAR-gamma dependent; i.e., it is stimulated by agonists of peroxisome proliferatoractivated receptors type gamma such as sterols, glucose, fibrates and chenodeoxycholic acid. ${ }^{14}$ The same factors regulate ATP-binding cassette transporter protein A1 (ABCA1) expression and phospholipid efflux from cells. ${ }^{2}$ Binding phospholipids and facilitating their transfer between lipoprotein in plasma, PLTP plays a key role in lipoprotein remodeling. However, its influence on nascent HDL formation is not clear. ${ }^{4}$ A diet rich in fat and a high level of glucose increase the rate of PLTP gene transcription and the activity of the protein. ${ }^{15}$ A similar effect occurred in patients treated with fibrates. ${ }^{16}$ Also, human apolipoproteins apoA-I, apoA-II and apoE, increased PLTP activity, whereas elevated levels of insulin triggered the opposite effect. ${ }^{15}$ PLTP concentration decreased during an increase in lipopolysaccharide (LPS) concentration in plasma due to the presence of a bacterial infection or after LPS injection into mice. At the same time, active inflammation caused an increase in the concentration of PLTP, and its concentration correlated with the level of C-reactive protein. ${ }^{17}$ PLTP level also increased with age, body mass index and triglyceride level. ${ }^{18}$ Higher values of PLTP have been observed in patients with type 1 diabetes and type 2 diabetes, as well as in patients with cardiovascular disease. ${ }^{19}$ On the other hand, plasma PLTP activity was independently decreased by acute hyperglycemia and hyperinsulinemia in humans, and these data do not support a direct role of short-term hyperglycemia in up-regulating plasma PLTP levels. ${ }^{20}$

PLTP protein is omnipresent in the human body. The highest concentrations have been observed in the lungs, placenta and ovaries. ${ }^{1}$ Most of the protein production occurs in the liver, which is responsible for $25 \%$ of plasma PLTP activity. Plasma PLTP exists in 2 forms: active, which has the ability to transfer phospholipids, and inactive. ${ }^{21}$ In healthy individuals the amount of the inactive form varies between $50-90 \%$ of the total protein. The inactive form is absent in people with hypoalphalipoproteinemia, e.g., in patients with Tangier disease, with lecithincholesterol acyltransferase (LCAT) deficiency, with apoA-I deficiency or family-deficient HDL. ${ }^{22}$ The inactive form is converted into the active form with the participation of apoE. These observations suggest the hypothesis that inactive PLTP is a reservoir for active PLTP, and can be quickly activated, but this requires further investigation.

Previous observations indicate that CETP is produced in the liver, spleen, adipose tissue, intestines, kidney, adrenal gland, heart and skeletal muscles. ${ }^{23}$ CETP is also present in cerebrospinal fluid and sperm. Significant expression of CETP in macrophages has been detected. ${ }^{3}$ The main factor increasing the concentration of CETP in plasma is consumption of food rich in cholesterol and fat. It has been shown that the concentration of CETP and its activity increases in rabbit serum after high-fat diet intake. ${ }^{24}$ It was recently proved that women with a waist circumference greater than $90 \mathrm{~cm}$ and men with a waist circumference greater than $100 \mathrm{~cm}$ have higher CETP activity than those with a smaller waist size. It was also shown that in patients who were on a well-defined diet containing a specified amount of cholesterol, both serum CETP activity and the concentration of CETP mRNA in adipocytes increased when the amount of cholesterol in the diet increased. The concentration of the CETP also depends on hormone levels, e.g., increased levels of corticosteroids or decreased levels of thyroid hormone lead to a reduction in the activity of CETP. ${ }^{25}$ Fibrates have been shown to reduce the activity of CETP.16 


\section{The role of PLTP and CETP in lipoprotein metabolism}

PLTP in serum mediates the transfer of phospholipids from triglyceride rich lipoproteins (e.g., VLDL or chylomicrons) to HDL, and thus is involved in the formation of chylomicrons or VLDL remnants, and in HDL maturation (Fig. 1). According to Albers et al., the mechanism presumably works by binding PLTP to phospholipids on the HDL surface, which causes the separation of small, lipidpoor particles comprised of apoA-I and phospholipids and leads to the formation of unstable surface HDL particles, which then leads to the fusion of unstable particles and the formation of a new, bigger, stable HDL particle. ${ }^{26}$ However, according to Settasatian et al., PLTP promotes the binding of 2 particles of HDL and then the diffusion into 2 parts, forming a particle of phospholipids containing apo-A and a stable, larger HDL particle. ${ }^{27}$

It is worth noting that there are conflicting reports about the impact of PLTP overexpression on HDL cholesterol levels. Based on some observational research, PLTP overexpression causes the total level of HDL to fall, but the level of pre $\beta$-HDL rises because of it. However, most observations show that the level of HDL increases with increased PLTP activity. ${ }^{26,27}$

Initially it was shown that PLTP played a key role in RCT from peripheral tissues, including transport from atherosclerotic plaque macrophages; the cholesterol is then

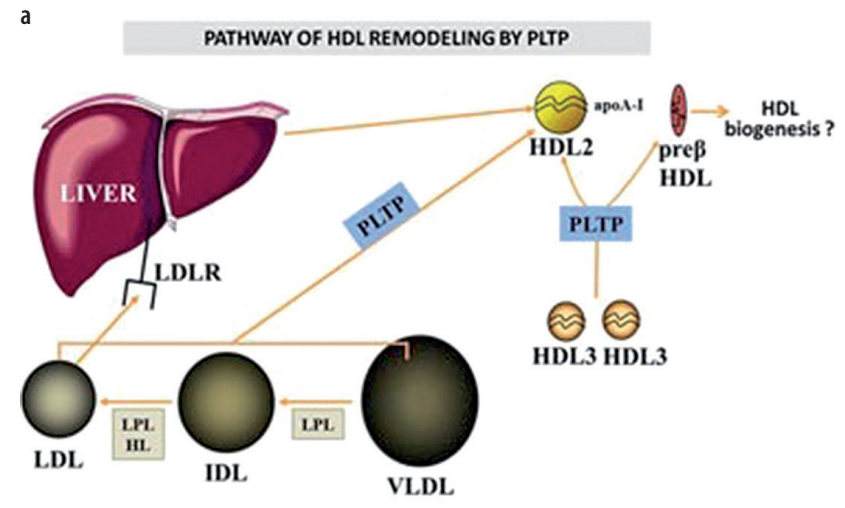

b

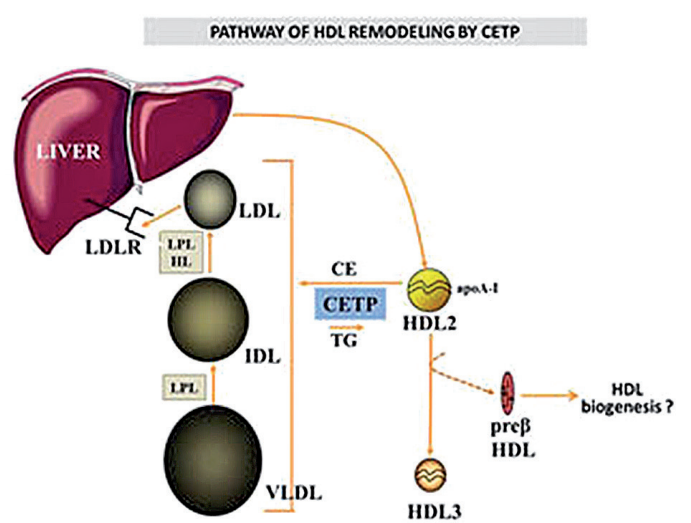

Fig. 1. Schematic representation of the pathway of HDL remodeling by the action of (a) PLTP and (b) CETP according to Zannis et al. ${ }^{28}$ transported to the liver and eliminated by biliary excretion. It is likely that cholesterol transport begins with the activation of the signaling pathways of ABCA1 proteins. Lee-Ruecert et al. studied ABCA1-dependent cholesterol efflux from peripheral macrophages from mice that lacked PLTP and showed that, compared to wild mice, cholesterol efflux was impaired. This effect was eliminated by strong stimulation of an ABCA1-dependent signaling pathway. ${ }^{29}$ Albers et al. have shown that the level of PLTP in macrophages is regulated by an up-regulation mechanism when cholesterol levels are high. ${ }^{11}$

Presumably, PLTP binds directly to protruding lipid domains of the cell membranes of macrophages and fibroblasts, which are in close proximity to ABCA1, causing JAK2 phosphorylation, which results in a further increase in PLTP connections and apolipoproteins to lipid domains, resulting in the dissolution and removal of the lipids from the cell and immediate transfer by PLTP particles accepting lipids, such as pre $\beta$-HDL. ${ }^{11}$ On the other hand, there are reports that active PLTP in the presence of apoA-I leads to the formation of faulty HDL particles that are less efficient in the uptake of cholesterol from peripheral tissues. ${ }^{30}$ It has also been shown that RCT is less efficient in transgenic mice overexpressing PLTP, which may indicate that elevated levels of PLTP may promote atherogenesis by the accumulation of cholesterol in the blood vessel wall. ${ }^{31}$

PLTP activity can be monitored by phospholipid carrying capacity from VLDL and LDL to HDL. PLTP activity is strongly correlated with the concentration of triglycerides in plasma and triglyceride content in HDL particles; this is probably due to the increased ability of phospholipid binding by HDL particles rich in triglycerides. ${ }^{32}$

CETP has the ability to transfer cholesteryl esters and triglyceride esters between all lipoproteins. However, its main task is transporting cholesteryl ester (CE) from HDL particles to VLDL, IDL and LDL, and triglycerides in the opposite direction (Fig. 1). The activity of the protein leads to the preservation of a specific lipid balance between lipoprotein fractions. This was demonstrated by a study by Barter et al., in HDL, LDL and VLDL particles were incubated in the presence of CETP. They observed CE transfer between each lipoprotein fraction, and "given equal concentrations of esterified cholesterol in all lipoprotein fractions, the relative probability of picking up (and depositing) a molecule of esterified cholesterol in HDL : VLDL : LDL is $28.9: 4.65: 1{ }^{\prime \prime}{ }^{33}$

Under physiological conditions, the activity of CETP is determined by the rate of metabolism of both HDL and LDL. ${ }^{34}$ In case of excessive CETP activity, modification of the lipid bi-directional transfer is minor, in contrast to a state of reduced CETP activity, which limits the exchange of lipids. Interestingly, under physiological conditions, when the concentration of VLDL is correct, CEs are transported mostly to LDL; when the concentration of VLDL is elevated, as it is in, e.g., diabetes, cholesteryl esters are transported mostly to VLDL particles, which are 
potentially strongly pro-atherosclerotic. It was also shown that the activity of CETP increases after a meal and is higher in patients with lipid disorders. As mentioned before, CETP activity is limited by the metabolism of LDL, as has also been shown by examining patients taking 3-hydroxy3-methylglutaryl-coenzyme reductase inhibitors.

The use of statin drug induces a significant reduction in total CETP activity and plasma mass concentration. Total CETP-mediated CE transport from high density lipoproteins to apoB-containing lipoproteins has been significantly reduced with drug therapy. ${ }^{35}$

There are 2 hypotheses pertaining the mechanism of CETP activity. One of them is based on the theory that CETP mediates the transfer of cholesteryl esters as its carrier between lipoprotein particles. At first CETP connects to the lipoprotein and there is an exchange of both cholesteryl esters and triglycerides. Then CETP dissociates from lipoproteins and circulates until it connects with another lipoprotein, when another exchange of CE and TG takes place. Thus, CETP activity maintains a balance among all lipoprotein levels. According to the second hypothesis, CETP participates in the exchange of cholesteryl esters and triglycerides by producing a tunnel. It is assumed that the $\mathrm{N}$-terminal portion of the protein combines with HDL first, then the C-terminal reacts with LDL or VLDL and forms a triple complex. This leads to changes in the shape of CETP, which form a hydrophobic tunnel that allows the transport of lipids between lipoprotein particles. ${ }^{36}$ It is worth noting that it has been shown that during the incubation of CETP with HDL particles, CETP has the ability to connect a few particles of CETP to one HDL particle. There was no evidence, however, that a CETP particle could attach to $2 \mathrm{HDL}$ particles, which seems to preclude the possibility of such a connection. ${ }^{37}$ Due to conflicting reports, more research is needed to definitively confirm one theory.

\section{PLTP and atherosclerosis}

Atherosclerosis progression is exacerbated by 3 main factors: increased levels of lipoproteins containing apolipoprotein B (apoB), vascular endothelial injuries, and increased levels of pro-inflammatory factors. The primary event in atherogenesis is cholesterol deposition in the subendothelial space of a vessel's wall. This cholesterol (mainly free, and less in the form of cholesteryl esters) originates from circulating lipoproteins. Physiologically, LDL, as well as remnants resulting from the hydrolysis of the TG contained in chylomicrons and VLDL, continually enter the subendothelial space and re-enter circulation. In some conditions, the subendothelial extracellular matrix retains cholesterol-rich lipoproteins and oxidative modifications of these lipoproteins occur. Many cellular and extracellular processes, including endothelial alterations, inflammatory responses and intracellular cholesterol accumulation in macrophages, lead to the formation of foam cells, then fatty streaks, and in the end atherosclerotic plaque. It is clear that a high level of atherogenic lipoproteins is associated with increased accumulation of them in vessel walls, thus the relationship between blood cholesterol and atherosclerosis is obvious. ${ }^{38}$ Elevated LDL levels and decreased HDL levels are independent risk factors for cardiovascular disease. PLTP and CETP are the main proteins involved in these molecules' metabolism.

\section{Animal models}

The majority of the animal model observations suggest that elevated levels of systemic PLTP promote atherogenesis. On the other hand, there are reports that locally elevated PLTP, for example in macrophages in arteries, may have an anti-atherogenic effect, and PLTP-deficient mice had a significantly lower risk of atherosclerosis. ${ }^{39}$ More research studying the effects of PLTP and the consequences of both excess and deficiency is needed. Today there is an increasing number of studies on the role of PLTP in the immune system. Lipopolysaccharides (LPS) are located on the cell surface of Gram-negative bacteria. LPS do not form stable particles but undergo numerous modifications thanks to PLTP. LPS play an important role in the activation of the immune system. LPS binding to LPS binding protein (LBP) activates Toll-like receptor 4, resulting in increased levels of pro-inflammatory cytokines and activation of the inflammation process. Simultaneously, activation of the immune system is also an important mechanism in atherogenesis. ${ }^{40}$

It was recently shown that there is an alternative route of LPS elimination, by binding to HDL and elimination in the liver. ${ }^{41}$ According to Hailman et al., PLTP may be a key mediator in binding LPS to HDL. ${ }^{42}$ Incubation of LPS with HDL in the presence of PLTP leads to the binding of the particles. It has also been shown that mice with reduced levels of PLTP have a higher ability to accumulate LPS in serum than mice with naturally high levels of PLTP. According to Gautier and Lagrost, PLTP may play a role in the reverse transport of LPS, as in the transport of cholesterol. ${ }^{41}$ Mice with naturally high levels of PLTP were observed to have lower concentration of LPS and they develop less severe inflammation. Moreover, the reverse LPS transport via HDL and PLTP may increase the rate of elimination of LPS by biliary excretion. Mice lacking PLTP had higher concentrations of LPS in the blood, lower resistance to septic shock and a lower survival rate than mice with normal concentration of PLTP in serum. ${ }^{41}$

\section{Human studies}

Albers et al. showed that PLTP activity in patients with sepsis or systemic inflammatory response syndrome was significantly higher compared to the control group. It was also confirmed that PLTP deficiency is associated with 
a poor response to inflammation and often causes fullblown sepsis leading to death. In turn, increased PLTP activity is associated with less tissue damage caused by bacterial infection. ${ }^{11}$ Their study showed that elevated levels of PLTP may be a compensatory mechanism of the inflammatory process and suggested that reduced levels of PLTP activity in patients with sepsis may be a bad prognostic factor. Increased levels of PLTP activity may be useful in the prevention and treatment of septic shock.

There is a growing interest in the role of PLTP in the development of other diseases. The PLTP concentration in cerebrospinal fluid (CSF) is reduced in the active phase of multiple sclerosis, and it increases in the inactive phase. Reduced PLTP activity in CSF is also observed in neurodegenerative diseases including Alzheimer's disease. In neoplastic disorders such as leukemias, gliomas, lung cancer, prostate cancer and breast cancer, PLTP activity in serum varies. In addition, it has been shown that the concentration of PLTP may be a prognostic factor for survival in patients with a breast cancer. ${ }^{43}$ Differences in serum PLTP levels in patients with cancer indicate that PLTP may be an important regulating factor in the neoplastic process.

\section{CETP and atherosclerosis}

\section{Animal models}

There are species of animals that naturally lack CETP activity, e.g., mice and rats, unlike rabbits, which have a very high activity of that protein. A decrease in HDL cholesterol and increased LDL and VLDL levels have been observed after human CETP was injected into mice. ${ }^{44}$ The formation of atherosclerotic plaque in transgenic mice that have a simian CETP gene has also been described; in this case atherosclerosis was the result of changes mediated by CETP activity in lipoproteins. ${ }^{45}$ On the other hand, there are studies suggesting that CETP has an anti-atherogenetic effect. The protective effect of CETP was also observed in transgenic mice with elevated triglyceride levels. ${ }^{46}$ Rabbits are very vulnerable to the development of atherosclerosis caused by a high-fat diet. When simultaneously providing such a diet and injections containing oligodeoxynucleotides with an antisense nucleotide sequence, significantly lower concentrations of CETP mRNA, lower total cholesterol and higher HDL were observed, which was associated with a lower risk of atherosclerosis. ${ }^{47}$ Studies have also shown a much lower incidence of atherosclerosis among rabbits treated with CETP inhibitors compared to rabbits who did not receive the drug, which was associated with significantly higher HDL levels and lower levels of non-HDL cholesterol..$^{48}$ On the other hand, inhibition of CETP activity and increases in HDL cholesterol in rabbits vaccinated with a CETP vaccine were not associated with prevention of aortic lesion development. ${ }^{49}$

\section{Human studies}

There is no unanimous standpoint about the role that CETP plays in the pathogenesis of atherosclerosis in humans. A CETP gene mutation in intron 14 that is present in up to $2 \%$ of Japanese people leads to reduced activity of the protein and elevated levels of HDL. Furthermore, a mutation in exon 15 that is found in $7 \%$ of Japanese people is also associated with elevated levels of HDL. However, studies conducted in Honolulu on a population of patients of Japanese origin with those mutations have not found a statistically significant difference in the incidence of heart disease or stroke. There is no evidence that the mutations themselves have a protective effect. The results suggest that the protective effect of CETP deficiency is associated with the presence of higher levels of HDL in these individuals. Moreover, the protective effect of the mutations disappears when HDL levels are lowered. ${ }^{34}$ On the other hand, many observations indicate that reduced levels of CETP have a protective effect on vessels. Several CETP gene mutations (e.g., TaqIB, I405V and 629C > A) that lead to reduced protein concentrations in serum have been identified so far. In a 2008 meta-analysis involving more than 113,000 respondents, it was shown that all of these mutations are associated with higher levels of HDL and lower risk of cardiovascular disease. ${ }^{50}$

\section{Therapeutic options}

The reports outlined above indicate that lower blood CETP concentration and lower CETP activity can have an anti-atherogenetic effect and thus can reduce the risk of cardiovascular disease. That fact creates a potential reference point for the evaluation of new drugs that are inhibitors of CETP. So far, 3 active compounds - torcetrapib, dalcetrapib and anacetrapib - have been tested on a large scale (Table 1). Toracetrapib works by increasing CETP's affinity for HDL, which ultimately leads to a reduction in the concentration of CETP that might participate in the transfer of TG between esterified cholesterol (EC) and lipoproteins. ${ }^{51}$ The efficacy of the drug was studied in the randomized, widespread ILLUMINATE study, which compared the effectiveness of atorvastatin alone with that of a combination of atorvastatin and torcetrapib. Initially, the results were very promising. HDL cholesterol levels in patients receiving the atorvastatin-torcetrapib combination were about $72 \%$ higher, but LDL cholesterol was $25 \%$ lower, compared to patients taking atorvastatin alone. Nevertheless, the study was terminated early because of a statistically significant higher mortality rate (93 deaths vs 59), both from cardiovascular (49 vs 35 people) and other causes (40 people vs 20 ). It is important to mention that among the participants taking toracetrapib, there were more deaths due to cancer and infections, although there was no statistical difference in the incidence of these diseases in the 2 groups. Moreover, the use of torcetrapib 
Table 1. Major studies utilizing CETP inhibitors in the prevention of atherosclerotic progression in human subjects (according to Quintão and Cazita, with modifications ${ }^{5}$ )

\begin{tabular}{|c|c|c|c|}
\hline $\begin{array}{l}\text { CETP } \\
\text { inhibitor }\end{array}$ & Human trials & Patients & Effect \\
\hline \multirow{4}{*}{ Torcetrapib } & RADIANCE & $\begin{array}{c}\text { patients with heterozygous familial } \\
\text { hypercholesterolemia or patients with mixed } \\
\text { dyslipidemia }\end{array}$ & no beneficial effect \\
\hline & ILLUSTRATE & in ACS patients & no beneficial effect \\
\hline & ILLUMINATE & $\begin{array}{c}\text { patients with history of cardiovascular disease } \\
\text { (including MI, stroke, ACS, unstable angina, PAD, } \\
\text { and cardiac revascularization), patients with type } 2 \\
\text { DM without previous cardiovascular disease }\end{array}$ & adverse off-target effects \\
\hline & $\begin{array}{l}\text { progression } \\
\text { of carotid } \\
\text { atherosclerosis }\end{array}$ & patients with familial hyper-cholesterolemia & no beneficial effect \\
\hline \multirow[b]{2}{*}{ Dalcetrapib } & $\begin{array}{l}\text { Dal- } \\
\text { VESSEL }\end{array}$ & $\begin{array}{l}\text { patients with CHD or CHD risk equivalent, with } \\
\qquad \mathrm{HDL}-\mathrm{C} \text { levels }<50 \mathrm{mg} / \mathrm{dL}\end{array}$ & reduction of arterial inflammation \\
\hline & Dal-OUTCOMES & $\begin{array}{c}\text { patients with recent } \mathrm{ACS} \text {, patients with stable } \mathrm{CHD} \text {, } \\
\mathrm{CHD} \text { risk equivalents or at elevated risk for } \mathrm{CHD}\end{array}$ & $\begin{array}{c}\text { in patients with recent ACS increase in } \mathrm{HDL} \text { cholesterol } \\
\text { levels but no effect on the risk of recurrent cardio-vascular } \\
\text { events }\end{array}$ \\
\hline Evacetrapib & ACCELERATE & patients at high-risk for vascular outcomes & $\begin{array}{c}\text { decrease in LDL cholesterol but no effect on the major } \\
\text { cardiovascular events }\end{array}$ \\
\hline \multirow[b]{2}{*}{ Anacetrapib } & DEFINE & patients with or at high risk for $\mathrm{CHD}$ & $\begin{array}{l}\text { very large increases in } \mathrm{HDL} \text { cholesterol and significant } \\
\text { reductions in } \mathrm{LDL} \text { cholesterol and other atherogenic } \\
\text { particles and an acceptable side-effect profile }\end{array}$ \\
\hline & REVEAL & $\begin{array}{l}\text { history of MI, cerebrovascular atherosclerotic } \\
\text { disease, PAD or DM with symptomatic CHD }\end{array}$ & $\begin{array}{l}\text { significant reduction of cardiovascular events; very large } \\
\text { increases in } \mathrm{HDL} \text { cholesterol; significant reductions in LDL } \\
\text { cholesterol and other atherogenic particles; reduced risk } \\
\text { of DM; insignificant increase in blood pressure }\end{array}$ \\
\hline
\end{tabular}

ACS - acute coronary syndrome; MI - myocardial infarction; PAD - peripheral vascular disease; CHD - coronary heart disease; DM - diabetes mellitus.

was associated with increased blood pressure, aldosterone, sodium and bicarbonate levels and decreased potassium levels. In animal studies the effect of torcetrapib on RCT remains unknown, as it has varying responses according to the animal species and models utilized. ${ }^{5}$

Another active compound which has been subjected to extensive clinical trials is dalcetrapib. It probably works by altering the conformation of CETP. Clinical reports show that dalcetrapib has no effect on either blood pressure or on the renin-angiotensin-aldosterone system. ${ }^{52}$ Dalcetrapib has been used in a large-scale randomized trial, called Dal-OUTCOMES. That study was also stopped prematurely - this time not because of side effects, but because of a lack of therapeutic effect. The drug, despite increasing HDL levels without an increase in LDL, did not bring the desired result of reducing cardiovascular risk.

Currently, high hopes are associated with a clinical trial of anacetrapib. As an addition to statin therapy, $100 \mathrm{mg}$ of anacetrapib daily more than doubles HDL levels and reduces LDL levels by $40 \%$; at the same time, it has no effect on blood pressure or aldosterone levels. Anacetrapib binds to a different site on CETP than dalcetrapib and induces a conformational change in the CETP molecule correlating with reduced CETP activity in humans. An anacetrapib-mediated CETP blockade can occur at the stage of the transfer of cholesteryl ester from smaller HDL3 particles to HDL2; it can also inhibit regeneration of HDL3 and formation of pre- $\beta$ HDL from HDL2 and decrease the transfer of CE from HDL to atherogenic LDL (Fig. 2). ${ }^{53}$ As noted above, CETP reduces circulating HDL levels by transferring cholesteryl ester (CE) from HDL to larger lipoproteins, such as chylomicrons, VLDL and LDL, in exchange for triglyceride. This creates smaller, cholesterol-depleted HDL (remodeling), which is potentially beneficial in removing excess tissue cholesterol, but also small, cholesterol-depleted LDL (SD-LDL), which is highly atherogenic. Inhibiting the latter without impairing HDL remodeling may be critical to the success of anacetrapib. ${ }^{53}$

Results of phase III clinical trial REVEAL has shown efficacy of anacetrapib from reducing non-HDL cholesterol which leads to decreased cardiovascular events in patients with atherosclerotic vascular disease. The main mechanism working is anacetrapib-mediated decrease of apoB-rich lipoproteins and decrease of lipoprotein a levels. Also it does not seem to dysfunctional HDL particles or changes in apolipoproteins that promote atherogenesis were produced by anacetrapib. In addition anacetrapib has beneficial effect on carbohydrate homeostasis, however slightly higher SBP and DBP were observed. ${ }^{54}$ Despite this, REVEAL has shown that anacetrapib could be useful therapeutic option for patients with high-risk coronary disease, especially for those who have statin intolerance or administration of statin is insufficient. 


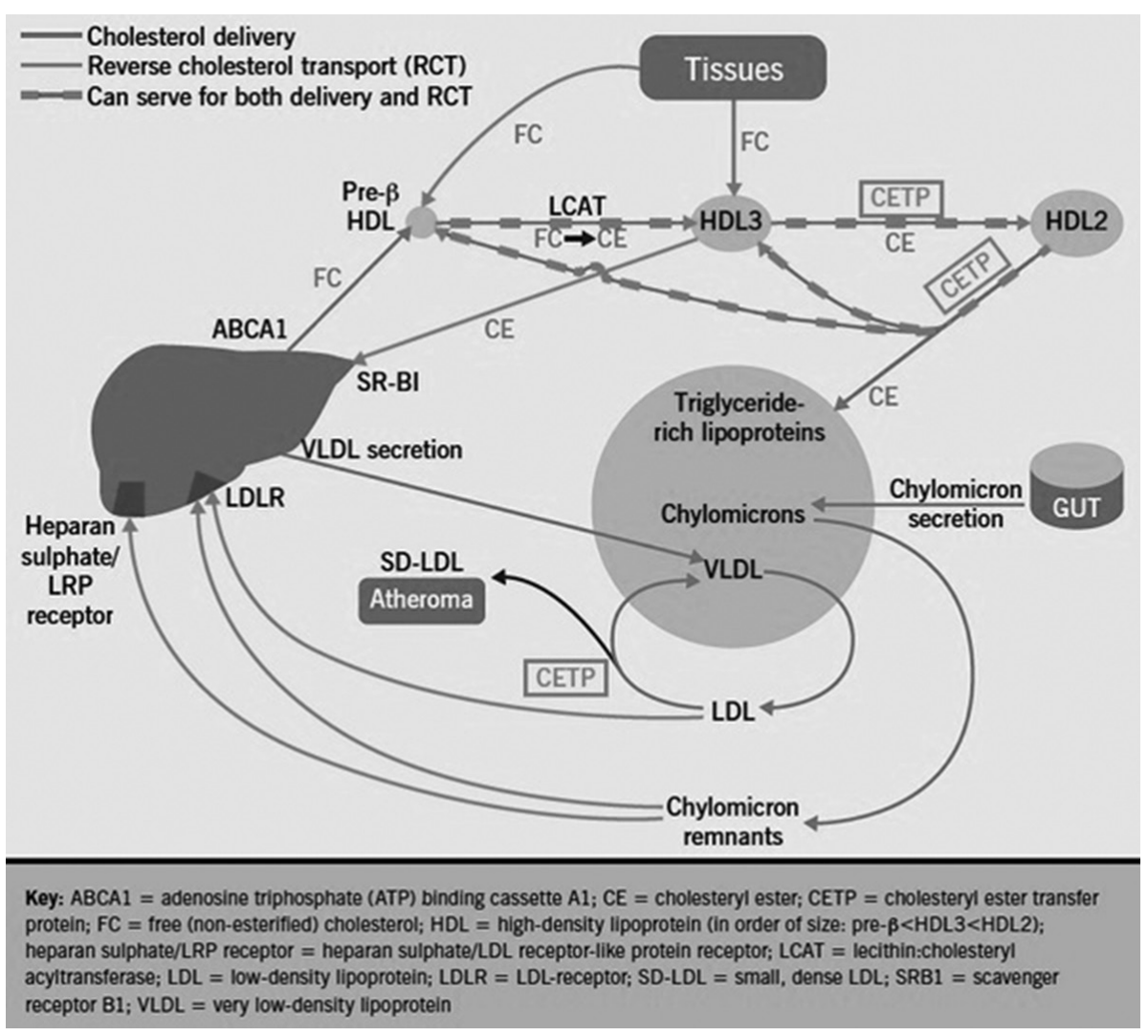

Fig. 2. The role of CETP in reverse cholesterol transport according to Durrington et al..$^{53}$

\section{Conclusions}

Lipid transfer proteins PLTP and CETP both play a major role in the metabolism of atherogenic and anti-atherogenic lipoproteins. Decreases in CETP mass or activity increase HDL and lower LDL levels. It seems reasonable to search for factors that may decrease the activity of CETP, and thus reduce the incidence of cardiovascular disease. At present, there are some controversies about the effect of PLTP on reverse cholesterol transport. Further studies are needed to clearly determine the impact of PLTP on the cardiovascular system.

\section{References}

1. Day JR, Albers JJ, Lofton-Day CE, et al. Complete CDNA encoding human phospholipid transfer protein from human endothelial cells. Biol Chem. 1994:269:9388-9391.

2. Huuskonen J, Olkonnen VM, Jauhiainien M, Ehnholm C. The impact of phospholipid transfer protein (PLTP) on HDL metabolism. Atherosclerosis. 2001;155:269-281.

3. Masson D, Jiang XC, Lagrost $L$, Tall AR. The role of plasma lipid transfer proteins in lipoprotein metabolism and atherogenesis. J Lipid Res. 2009;50:201-206. doi: 10.1194/jlr.R800061-JLR200

4. Ji A, Wroblewski JM, Webb NR, van der Westhuyzen DR. Impact of phospholipid transfer protein on nascent high-density lipoprotein formation and remodeling. Arterioscler Thromb Vasc Biol. 2014;34: 1910-1916.

5. Quintão EC, Cazita PM. Lipid transfer proteins: Past, present and perspectives. Atherosclerosis. 2010;209:1-9.

6. Jiang $X \mathrm{C}$, Jin $\mathrm{W}$, Hussain MM. The impact of phospholipid transfer protein (PLTP) on lipoprotein metabolism. Nutr Metab. 2012;9(1):75.
7. Di Bartolo B, Takata K, Duong M, Nicholls SJ. CETP inhibition in CVD prevention: An actual appraisal. Curr Cardiol Rep. 2016;18(5):43.

8. Bruce C, Beamer LJ, Tall AR. The implications of the structure of the bactericidal/permeability-increasing protein on the lipid-transfer function of the cholesteryl ester transfer protein. Curr Opin Struct Biol. 1998;8:426-434.

9. Yamashita S, Hirano K, Sakai N, Matsuzaw Y. Molecular biology and pathophysiological aspects of plasma cholesteryl ester transfer protein. Biochim Biophys Acta. 2000;1529:257-275.

10. Tu AY, Deeb SS, Iwasaki L, Day JR, Albers JJ. Organization of human phospholipid transfer protein gene. Biochem Biophys Res Comm. 1995;207:552-558.

11. Albers JJ, Vuletic $S$, and Cheung MC. Role of plasma phospholipid transfer protein in lipid and lipoprotein letabolism. Biochim Biophys Acta. 2012;1821:345-357.

12. Beamer LJ, Carrol SF, Eisenberg D. Crystal structure of human BPI and two bound phospholipids at 2.4 angstrom resolution. Science. 1997;276:1861-1864.

13. Qiu XY, Mistry A, Ammirati MJ. Crystal structure of cholesteryl ester transfer protein reveals a long tunnel and four bound lipid molecules. Nat Struct Mol Biol. 2007;14:106-113.

14. Bouly M, Masson D, Gross B, et al. Induction of the phospholipid transfer protein gene accounts for the high density lipoprotein enlargement in mice treated with fenofibrate. J Biol Chem. 2001;276:25841-25847.

15. Riemens SC, van Tol A, Sluiter WJ, Dullaart RP. Plasma phospholipid transfer protein activity is lowered by $24-\mathrm{h}$ insulin and acipimox administration: Blunted response to insulin in type 2 diabetic patients. Diabetes. 1999;48:1631-1637.

16. Lewis GF. Are the lipid-modifying effects of fibrates mediated by alterations in plasma lipid transfer activity? Clin Sci. 2006;111:185-187.

17. Levels JH, Pajkrt D, Schultz M, et al. Alterations in lipoprotein homeostasis during human experimental endotoxemia and clinical sepsis. Biochim Biophys Acta. 2007;1771:1429-1438.

18. Tzotzas T, Desrumaux C, Lagrost L. Plasma phospholipid transfer protein (PLTP): Review of an emerging cardiometabolic risk factor. Obes Rev. 2009;10:403-411. 
19. Desrumaux C, Athias A, Bessede G, et al. Mass concentration of plasma phospholipid transfer protein in normolipidemic, type lla hyperlipidemic, type IIb hyperlipidemic, and non-insulin-dependent diabetic subjects as measured by a specific ELISA. Arterioscler Thromb Vasc Biol. 1999;19:266-275.

20. Oomen PH, van Tol A, Hattori H, Smit AJ, Scheek LM, Dullaart RP. Human plasma phospholipid transfer protein activity is decreased by acute hyperglycaemia: Studies without and with hyperinsulinaemia in type 1 diabetes mellitus. Diabet Med. 2005;22:768-774.

21. Oka T, Kujiraoka T, Ito M, et al. Distribution of phospholipid transfer protein in human plasma: presence of two forms of phospholipid transfer protein, one catalytically active and the other inactive. J Lipid Res. 2000;41:1651-1657.

22. Oka T, Yamashita S, Kujiraoka T, et al. Distribution of human plasma PLTP mass and activity in hypo- and hyperalphalipoproteinemia. J Lipid Res. 2002;43:1236-1243.

23. Drayna, D, Jarrnagin AS, McLean J, et al. Cloning and sequencing of human cholesteryl ester transfer protein cDNA. Nature. 1987;327: 632-634.

24. Son YS, Zilversmit DB. Increased lipid transfer activities in hyperlipidemic rabbit plasma. Arteriosclerosis. 1986;6:345-351.

25. Dedecjus M, Masson D, Gautier T, et al. Low cholesteryl ester transfer protein (CETP) concentration but normal CETP activity in serum from patients with short-term hypothyroidism. Lack of relationship to lipoprotein abnormalities. Clin Endocrinol. 2003;58:581-588.

26. Albers JJ, Wolfbauer G, Cheung MC, et al. Functional expression of human and mouse plasma phospholipid transfer protein: Effect of recombinant and plasma PLTP on HDL subspecies. Biochim Biophys Acta. 1995;1258:27-34.

27. Settasatian N, Duong M, Curtiss LK, et al. The mechanism of the remodeling of high density lipoproteins by phospholipid transfer protein. J Biol Chem. 2001;276: 26898-26905.

28. Zannis VI. et al. HDL Biogenesis, Remodeling, and Catabolism. In: von Eckardstein A, Kardassis D, eds. High Density Lipoproteins. Handbook of Experimental Pharmacology, vol. 224. Springer, Cham; 2015.

29. Lee-Rueckert M, Vikstedt R, Metso J, Ehnholm C, Kovanen PT, Jauhiainen $\mathrm{M}$. Absence of endogenous phospholipid transfer protein impairs ABCA1-dependent efflux of cholesterol from macrophage foam cells. J Lipid Res. 2006;47:1725-1732.

30. Moerland M, Samyn H, van Gent T, et al. Acute elevation of plasma PLTP activity strongly increases pre-existing atherosclerosis. Arterioscler Thromb Vasc Biol. 2008;28:1277-1282.

31. Moerland M, Samyn $H$, van Gent T, et al. Atherogenic, enlarged, and dysfunctional HDL in human PLTP/apoA-I double transgenic mice. J Lipid Res. 2007;48:2622-2631.

32. Cheung MC, Wolfbauer G, Deguchi H, Fernandez JA, Griffin JH, Albers JJ. Human plasma phospholipid transfer protein specific activity is correlated with HDL size: Implications for lipoprotein physiology. Biochim Biophys Acta. 2009;1791:206-211.

33. Barter PJ, Hopkins GJ, Calvert GD. Transfers and exchanges of esterified cholesterol between plasma lipoproteins. Biochem J. 1982;208:1-7.

34. Barter PJ, Brewer Jr HB, Chapman MJ, Hennekens CH, Rader DJ, Tall AR. Cholesteryl ester transfer protein. A novel target for raising HDL and inhibiting atherosclerosis. Arterioscler Thromb Vasc Biol. 2003;23: 160-167.

35. Guerin M, Lassel TS, Le Goff W, Farnier M, Chapman MJ. Action of atorvastatin in combined hyperlipidemia: preferential reduction of cholesteryl ester transfer from HDL to VLDL1 particles. Arterioscler Thromb Vasc Biol. 2000;20:189-197.

36. Zhang L, Yan F, Zhang S, et al. Structural basis of transfer between lipoproteins by cholesteryl ester transfer protein. Nat Chem Bio. 2012; 8:342-349.

37. Zhang $M$, Charles $R$, Tong $H$, et al. HDL surface lipids mediate CETP binding as revealed by electron microscopy and molecular dynamics simulation. Sci Rep. 2015;5:1-8. doi:10.1038/srep08741

38. Tabas I. Cholesterol and phospholipid metabolism in macrophages. Biochim Biophys Acta. 2000;1529:164-174.

39. Valenta DT, Bulgrien JJ, Bonnet DJ, Curtiss LK. Macrophage PLTP is atheroprotective in LDLr-deficient mice with systemic PLTP deficiency. J Lipid Res. 2008;49:24-32.

40. Miller SI, Ernst RK, Bader MW. LPS, TLR4 and infectious disease diversity. Nat Rev Microbiol. 2005;3:36-46.

41. Gautier T, Lagrost L. Plasma PLTP (phospholipid-transfer protein): an emerging role in oka'reverse lipopolysaccharide transport' and innate immunity. Biochem Soc Trans. 2011;39: 984-988.

42. Hailman E, Albers JJ, Wolfbauer G, Tu AY, Wright SD. Neutralization and transfer of lipopolysaccharide by phospholipid transfer protein. J Biol Chem. 1996;271:12172-12178.

43. Ferkingstad $\mathrm{E}$, Frigessi $\mathrm{A}$, Lyng $\mathrm{H}$. Indirect genomic effects on survival from gene expression data. Genome Biol. 2008;9:R58-R72.

44. Jiang XC, Masucci-Magoulas L, Mar J, et al. Down-regulation of mRNA for the low density lipoprotein receptor in transgenic mice containing the gene for human cholesteryl ester transfer protein: mechanism to explain accumulation of lipoprotein B particles. J Biol Chem.1993;268:27406-27412.

45. Marotti KR, Castle CK, Boyle TP, Lin AH, Murray RW, Melchior GW. Severe atherosclerosis in transgenic mice expressing simian cholesteryl ester transfer protein. Nature. 1993;364:73-75.

46. Kako Y, Massé M, Huang LS, Tall AR, Goldberg IJ, et al. Lipoprotein lipase deficiency and CETP in streptozotocin-treated apoB-expressing mice. J Lipid Res. 2002;43:872-877.

47. Sugano M, Makino N, Sawada S, et al. Effect of antisense oligonucleotides against cholesteryl ester transfer protein on the development of atherosclerosis in cholesterol-fed rabbits. $J$ Biol Chem. 1998;273:5033-5036.

48. Okamoto H, Yonemori F, Wakitani K, Minowa T, Maeda K, Shinkai H. A cholesteryl ester transfer protein inhibitor attenuates atherosclerosis in rabbits. Nature. 2000;406:203-207.

49. Aghebati T, Badiee $A$, Mohammadpour $A H$, et al. Anti-atherosclerosis effect of different doses of CETP vaccine in rabbit model of atherosclerosis. Biomed Pharmacother. 2016; 81,468-473.

50. Thompson A, Di Angelantonio E, Sarwar N. Association of cholesteryl ester transfer protein genotypes with CETP mass and activity, lipid levels, and coronary risk. JAMA.2008;299:2777-2788.

51. Clark RW, Ruggeri RB, Cunningham D, Bamberger MJ. Description of the torcetrapib series of cholesteryl ester transfer protein inhibitors, including mechanism of action. J Lipid Res. 2006;47:537-552.

52. Stroes ES, Kastelein JJ, Benardeau A, et al. Dalcetrapib: No off-target toxicity on blood pressure or on genes related to the renin-angiotensin-aldosterone system in rats. Br J Pharmacol. 2009;158:1763-1770.

53. Durrington PN. Cholesteryl ester transfer protein (CETP) inhibitors. Br J Cardiol. 2012;19:126-133.

54. Filippatos TD, Kei A, Elisaf MS. Anacetrapib, a new CETP inhibitor: The new tool for the management of dyslipidemias? Diseases. 2017;5:21. doi:10.3390/diseases5040021 